\title{
Editorial: Special issue in memory of Kenneth J. Arrow
}

\author{
Eric Maskin ${ }^{1} \cdot$ Amartya Sen $^{1} \cdot$ Kotaro Suzumura $^{2}$ \\ Published online: 26 February 2020 \\ ○ Springer-Verlag GmbH Germany, part of Springer Nature 2020
}

Kenneth J. Arrow, a giant in economics and in twentieth-century thought more generally, died on February 21, 2017 at the age of 95. With his landmark monograph Social Choice and Individual Values, Arrow created modern social choice theory. He was also a founding father of the Society for Social Choice and Welfare-which publishes this journal—and its first president.

As profound admirers and close friends of Ken's, the three of us proposed that Social Choice and Welfare should publish a special issue in his memory. We were grateful that SCW's editorial board accepted our proposal and asked us to serve as guest editors.

There are three sorts of articles in this special (double) issue. First, each guest editor has a piece that combines personal reminiscence with some specific thoughts on social choice theory. Second, there are invited contributions from several major figures in the field who have long-standing connections to Ken. Finally, there are articles submitted in response to the Call for Papers published in the journal. Needless to say, all papers were rigorously refereed and edited.

We are deeply grateful to Marc Fleurbaey, the journal's former coordinating editor, whose editorial participation was essential to the issue's completion.

\section{Post scriptum}

We are heartbroken that our dear friend and collaborator Kotaro Suzumura died of pancreatic cancer on January 15, 2020, only a few weeks after the editing for this special issue was completed. We can now acknowledge that Kotaro was the prime mover behind this project: he conceived the idea and did the lion's share of the editorial work. When illness prevented him from continuing, Marc Fleurbaey generously took over as the main steward of the issue. Many, many thanks to you, Marc.

Eric Maskin

emaskin@fas.harvard.edu

Amartya Sen

asen@fas.harvard.edu

1 Harvard University, Cambridge, MA 02138, USA

2 School of Political Science and Economics, Waseda University, 1-6-1 Nishi Waseda, Shinjuku-ku, Tokyo 169-8050, Japan 
Kotaro's important contributions to social choice theory will no doubt be memorialized appropriately in due course. But, for now, we are extending the dedication of this special issue to a second great scholar, Kotaro Suzumura.

Eric Maskin

Amartya Sen

Publisher's Note Springer Nature remains neutral with regard to jurisdictional claims in published maps and institutional affiliations. 